\title{
Dare to share your information!
}

\author{
by Trina Innes ${ }^{1}$
}

We all create and use science and technology (S\&T) data. Unfortunately, information that is tied up within organizations is perceived to not exist. Information management and knowledge management activities help make information more accessible and useable. This article highlights forest sector challenges in information management, demonstrates the importance of addressing these challenges and presents some initiatives that will help ensure forest sector organizations are also knowledge-based organizations

Key words: information management, knowledge management, science and technology, information systems

Nous créons et utilisons tous des données scientifiques et techniques. Malheureusement, l'information qui est conservée au sein des organisations, est perçue comme n'existant pas. La gestion de l'information et les activités de gestion des connaissances aident à rendre l'information plus accessible et plus utilisable. Cet article met en relief les défis du secteur forestier en matière de gestion de l'information, illustre l'importance de tenir compte des ces défis et présente quelques initiatives qui aideront à assurer que les organisations du secteur forestier soient également des organisations pouvant compter sur les connaissances.

Mots-clés: gestion de l'information, gestion des connaissances, sciences et technologies, systèmes d'information

When a man's knowledge is not in order, the more of it he has the greater will be his confusion. ${ }^{2}$

\section{Introduction}

We all create and use science and technology (S\&T) datafiling cabinets and hard drives full of it! People often worry that the costs of managing and sharing information is too high. But what about the costs of not doing it or doing it poorly? How much information is lost when employees move on? How much effort is duplicated because no information is available on past research?

Scientists develop research over many years. Other scientists use historical work to support and augment new research. Land managers require credible, current information to support decisions. Unfortunately, information that is tied up within organizations is perceived to not exist. Information that is not easily accessed or poorly presented will not be consulted. How many decisions are made using weak information?

Information management involves processes through which information is made known. Processes include planning, collecting, organizing, disseminating and using information. Knowledge management involves the retrieval and distribution of information in a form that increases its usefulness to end-users. Information systems and technology provide tools to enable efficient, effective delivery of information and knowledge.

In addition to highlighting $S \& T$ information challenges facing the forest sector, this article outlines universal agreement on the need for improved information management and presents some initiatives that will help ensure forest sector organizations are also knowledge-based organizations.

\footnotetext{
${ }^{1}$ Natural Resources Information Specialist, Southern Interior Forest Extension and Research Partnership, 478 St. Paul Street, Kamloops, British Columbia V2C 2J6. E-mail: trina.innes@siferp.org

${ }^{2}$ Herbert Spencer (1020-1903) in The Principles of Sociology (c. 1886).
}

\section{Information Manage- ment: Is it Really That Important?}

Forest information is geographically distributed across Canada-in government, nongovernment, industry, First Nations and academic organizations. In absence of a comprehensive online source of information on information gaps and past research, organizations with limited fund-

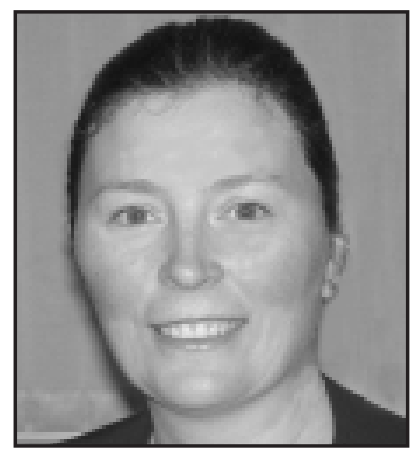

Trina Innes ing risk investing in low priority projects or duplicating past research.

Field practitioners, stakeholders and policy developers are calling for improvements to the quality of information and access to information needed to guide decisions and investments. Canadian forest research organizations are losing their organizational memory - a large portion of the workforce will retire in the next 10 years. Organizations will lose connections between researchers and the projects they created. Forestry organizations in Canada and around the world share in these and many other information-related challenges.

In British Columbia, the Southern Interior Forest Extension and Research Partnership combined grassroots meetings and a comprehensive consultative process to identify knowledge gaps in the natural resource sector (Hollstedt 2000, Innes 2001). Their investigations identified a provincial need to:

- Promote provincial leadership, collaboration and cooperation in information sharing.

- Use guidelines that adhere to international standards and protocols.

- Compile catalogues of information and open access to their content.

- Identify, develop and implement a suitable technical infrastructure.

- Promote and enable local information management activities. 
- Collaborate and share development of tools, technologies, and information collection.

- Establish guidelines relating to copyright and intellectual property.

A review of best management practices for the Ontario Ministry of Environment suggests a more strategic approach for managing the environment and associated information is required (IBM Consulting Group 2000). The report recommends building a comprehensive environmental Knowledge Management strategy that builds a more informed public and links all business functions. They recommend a strategy that builds capacity to share information internally and externally, re-establishes or builds partnerships between the scientific, research and technical communities, and invests in tools and technologies to improve information and knowledge exchange.

Within the Canadian Forest Service—a S\&T agency with over 100 years of new knowledge holdings-Simard (2000) stresses the need to pay close attention to those that create new knowledge, managing knowledge assets and improving knowledge sharing.

The Canadian Council of Forest Ministers (CCFM 2000) recognized informed decision-making as one of six criteria necessary for achieving sustainable forest management. They believe society must learn and understand environmental issues to be part of fair and effective decision-making processes. In support of this, several indicators relating to information and extension are incorporated into the national criteria and indicator framework and associated National Forest Strategy. Key measures relate to:

- Investments in forest-based research and development and information.

- Total effective expenditure on public forestry education.

- Mutual learning mechanisms and processes.

The CCFM also organized The Coalition for the Advancement of Science and Technology in the Forest Sector (FORCAST). Their mission is "To achieve forest sector recognition and commitment to knowledge and innovation as crucial elements to sound forest stewardship and global competitiveness." They do this by promoting improved communication and coordination between S\&T organizations.

Improving the availability of information was identified as a worldwide need in Agenda 21-an international cooperative plan of action for sustainable development adopted in 1992 by more than 178 countries at the United Nations Conference on Environment and Development (UNCED). Chapter 40 of Agenda 21 established a need for a) strengthening and improving mechanisms for processing and exchanging information, and b) strengthening capacities for handling and communicating information. Agenda 21 requests governments to promote activities that will:

- Produce information usable for decision-making.

- Establish standards for handling and sharing information.

- Strengthen electronic links to a variety of information sources.

Clearly, there is a need for improved management of information provincially, nationally and internationally. In these times of increasing financial pressures, it is important to address these challenges. To accomplish this, it is important to expand our awareness and understanding of information management, and improve communication and cooperation between organizations that are developing approaches, tools and technologies.

\section{Taking up the Challenge: Provincial, National and International Initiatives}

A multiplicity of regional, provincial and national agencies and partnerships are developing approaches for managing natural resource information. There is much for organizations to gain - experience, tools, technologies, cost savings — by using established approaches and building links to existing initiatives. Some key tools and technologies are identified in Exhibit 1. Some initiatives of interest to the forest sector are identified below.

\section{Southern Interior Forest Extension and Research Partnership}

The Southern Interior Forest Extension and Research Partnership (SIFERP; Web site: www.siferp.org) is facilitating the development of the Natural Resources Information Network (NRIN; Web site: nrin.siferp.org) in British Columbia with a variety of partners. Launched in 2001, NRIN helps users identify, acquire, and share natural resources informationpublications, organizations, events and researchers-relating to British Columbia. SIFERP is using MetaStar Enterprise as the underlying NRIN software application and sub-set of the Federal Geographic Data Committee metadata standard to catalogue information resources.

Information systems alone do not result in effective sharing and application of information. SIFERP provides extension services to assist organizations in moving information and technology into practice. Recognizing the opportunities afforded by technological transformation of the workplace, SIFERP also uses other Internet tools to facilitate internal and external operations separated by time and space.

"eProject" (www.eproject.com) is a Web-based project management tool that allows teams to share tasks, documents, discussions, schedules, web addresses and polls. It is a tool for managing multiple or complex projects involving teams that are separated by time or distance through a shared interface.

"WebEx"(www.webex.com) is an interactive online meeting room. Accompanied by a teleconference, this technology allows meeting attendees to jointly view presentations, navigate Web sites and share documents. This tool can also be used to provide live demos and training on any software application.

"LISTSERV" (www.lsoft.com) software allows users to create and maintain email mailing lists. Many forms of mailing lists, including newsletter lists, announcement lists and interactive discussion lists are leveraged to improve communications between staff, clients and organizations.

\section{Coalition for the Advancement of Science and Technology in the Forest Sector}

As a member of the Coalition for the Advancement of Science and Technology in the Forest Sector (FORCAST), SIFERP partnered with FORCAST in the creation of the FORCAST Strategic Knowledge System (SKS). Based on a selection of SIFERP's tools including NRIN, the SKS includes an Internet portal of strategic S\&T information. The SKS helps FORCAST communicate internally with their 
Managing information assets requires hardware, software, technical and human networks for collecting information and making it available. The first step involves describing and cataloguing information. This is accomplished by using a metadata standard. Metadata—also defined as "information about data"-describes an information resource (e.g., title, author, abstract, publisher, etc.). Metadata can also tell users how to access information. Using an international metadata standard not only reduces the time developing standards, it helps ensure that information is easily shared between compatible information systems. A number of international metadata standards help users organize information.

Dublin Core

http://www.dublincore.org

Government Information Locator Service (GILS)

http://www.gils.net

Federal Geographic Data Committee (FGDC)

http://www.fgdc.gov

Methods for standardizing the interoperability of computer systems and software are worth exploring. One exciting development is a new computer "metalanguage" called extensible markup language (XML). It allows users to create a customized language for exchanging information. XML is a license-free, platform-independent language that is widely supported. Visit http://www.xml.com for more information.

Also worth researching is the ANSI/NISO Z39.50 search and retrieval protocol. This is an open communications protocol standard that brings information from diverse sources together over the Internet for common search and retrieval.

While some organizations are developing open-source solutions for managing and exchanging information, commercial software solutions are also available.

Product

ArcCatalog

MetaManager

MetaStar Enterprise

SSMS

Xt Metadata Editor

\author{
Company \\ ESRI \\ Compusult \\ Blue Angel Technologies \\ RTSE USA \\ US Geological Survey
}

URL

www.esri.com

www.compusult.com

www.blueangeltech.com

http://www.rtseusa.com

http://geochange.er.usgs.gov/pub/tools/metadata membership and promote and advocate forest sector S\&T activities across Canada. For more information visit: http:// forcast.forest.ca

\section{National Forest Information System}

In August 2000, the Canadian Council of Forest Ministers (CCFM) agreed to establish a technology information infrastructure called the National Forest Information System (NFIS). It will provide access to geographically based forest resources information and Web-based tools to simplify the monitoring, integrating and reporting on forest resources. The NFIS is intended to meet Canada's commitment to provide a comprehensive picture of Canadian forest practices. For more information on this initiative visit: www.nfis.org

\section{Canadian Information System for the Environment}

Federal Environment Minister David Anderson created the Task Force on a Canadian Information System for the Environment (CISE) in October 2000. While in its infancy, this system will enable timely access to a broad range of environmental data and information-including NFIS content - to support decision-making. It is recommended that this site serve as the Canadian node for the Global Biodiversity Information Facility. For more information visit www.ec.gc.ca/cise

\section{Biodiversity Clearinghouse Mechanism}

The Canadian Biodiversity Information Network is Canada's node on the International Clearing House Mechanism (CHM) for the Convention on Biological Diversity (www.cbin.ec.gc.ca). CHM helps ensure that all governments have access to information and technologies relating to biodiversity. For more information visit www.biodiv.org

\section{Global Forest Information System}

The International Union of Forest Research Organizations (IUFRO) formalized a task force in 1998 to bring together an Internet-based metadata service. It coordinates worldwide access to forest-related information in the form of the Global Forest Information System. For more information visit www.gfis.org

It is impossible to list all organizations with information systems in place or under development, but some other systems of interest include: GeoConnections, Cordlink, Environment Canada (The Green Lane; Stewardship Centre), Conservation Data Centres and the Columbia Basin Information Network.

\section{What's Next?}

Recognizing the advantages of improved information management, many organizations have launched information systems. Some regional and provincial systems are developing independently using a variety of metadata standards and paying limited attention to inter-operability. Due to limited collaboration, opportunities to build comprehensive information sources and leverage technology applications are reduced. S\&T providers and clients have expressed an interest in overcoming these challenges.

FORCAST is launching a national S\&T discussion group and planning a workshop in 2002. Targeted at organizations that are developing information systems, this workshop will increase awareness of existing systems, expertise, and initiatives underway in Canada.

SIFERP is planning a conference in early winter 2002. Targeted at both information providers and users, this conference will share approaches, experiences, tools and technologies for managing natural resource information in Canada. 
The time has come to address the shortcomings of S\&T information infrastructure in Canada's forest sector by daring to share information. Organizations advocating increased funding will experience more success by demonstrating exceptional management, use and conveyance of information assets. To position the Canadian forest sector as a leader in the emerging knowledge-based economy, we must emphasize and support knowledge sharing and exchange activities in all organizations and work to build an effective information and communications infrastructure.

\section{References}

Canadian Council of Forest Ministers (CCFM). 2000. Criteria and Indicators of Sustainable Forest Management in Canada. Natural Resources Canada. 140 p.
Hollstedt, C. 2000. Science, Innovation and Sustainability: Investing in British Columbia's Knowledge-based Natural Resource Sector. Southern Interior Forest Extension and Research Partnership. SIFERP Series No. 2.70 p. [Online] http://www.siferp.org/pubs/siferpseries/ss2/ IBM Consulting Group. 2001. Managing the Environment Report: A Review of Best Practices. Executive Resource Group, Ministry of Environment, Government of Ontario. [Online] http://www.ene.gov.on. ca/envision/ergreport/index.htm

Innes, T. 2001. Organizing for innovation. LINK 2(3): 8.

Simard, A. 2000. Managing knowledge at the Canadian Forest Service. Canadian Forest Service, Natural Resources Canada. 88 p. 